\title{
A PROdUÇÃo de CONHECIMENTO E VERDAdE NO CONTEMPORÂNEO
}

\author{
Eurípedes Costa do Nascimento ${ }^{\star}$
}

\begin{abstract}
Resumo
O presente artigo procura refletir sobre a produção de conhecimento e verdade no contemporâneo articuladas com o conceito de biopoder e a imersão do sujeito na construção desse conhecimento. Mediante tais reflexões, chega-se à conclusão que as ciências humanas precisam rever o lugar cômodo do cientificismo acadêmico para repensar e relativizar a verdade visando a transformação das práticas sociais objetivantes e historicamente construidas para uma outra forma de conhecimento capaz de questionar as instâncias instituídas nos campos do saber e do poder a fim de propor novos paradigmas cientificos e uma subjetividade mais autêntica e com novas significações.
\end{abstract}

Palavras-chave: ciências humanas; verdade; conhecimento; subjetividade.

\section{ThE TRUTH AND KNOWLEDGE PRODUCTION IN THE CONTEMPORARY}

\begin{abstract}
This paper aims to reflect about the truth and knowledge production in the contemporary articulated with the biopower concept and the immersion of the subject in the production of this knowledge. It is concluded by means of a such reflections that the human sciences need to review the snugness of academic scientism to rethink and relativize the truth aiming to the transformation of the objective social practices and built historically to another knowledge way able to question the instituted instances by the power and knowledge in order to propose new scientific paradigms and a subjectivity more authentic and with new meanings too.
\end{abstract}

Keywords: human sciences; truth; knowledge, subjectivity.

\footnotetext{
^ Doutorando em Psicologia e Sociedade pela Unesp (Universidade Estadual Paulista), Campus de Assis, com bolsa de financiamento concedida pela Fapesp (processo 2009/00641-0). Endereço: Avenida Doutor Doria, 129 (Vila Ouro Verde). Cep: 19815-050 Assis, SP.

E-mail: nascimentoec@gmail.com
} 


\section{INTRODUÇão}

O presente artigo procura refletir sobre a produção de conhecimento e verdade no contemporâneo a partir de algumas leituras realizadas na obra de Michel Foucault, pois, acreditamos que suas considerações a respeito do saber e do poder presentes no espaço social podem nos possibilitar a compreensão do sujeito como objeto de manipulação desse poder que institucionaliza verdades tanto nas atividades do senso comum, como nas atividades acadêmicas responsáveis pela difusão do debate e propagação do conhecimento científico. Michel Foucault nos traz importantes considerações sobre esse modus operandi da verdade a partir de investigações acerca das práticas sociais construídas na história das civilizações. Foucault ao longo de sua extensa obra sempre se preocupou em desvelar os modos de funcionamento que constituem as relações humanas no espaço social, tomando como eixo norteador de suas análises a problemática do corpo e da sexualidade como constituintes operacionais da subjetividade intermediada pelas ações políticas do saber e do poder na produção de verdade.

Nesse sentido, o interesse pela problemática do corpo e da sexualidade levou o autor a considerar que a constituição da subjetividade moderna está relacionada às elaborações de verdade historicamente construídas que governam e controlam os sujeitos e seus desejos mais íntimos num sistema de dominação, controle e aprisionamento da consciência. Segundo Foucault $(1979,1984)$ esse controle social exercido sobre o corpo e consequentemente sobre o sujeito, possibilitou a formação de uma "sociedade disciplinar" que elabora leis, códigos morais e comportamentos "desejáveis" com a finalidade de controlar cada atividade realizada pelo sujeito em sua particularidade, determinando, inclusive, o que é falso e verdadeiro conforme seus interesses na manutenção de uma fictícia estabilidade administrada por uma "microfísica do poder".

Partindo dessas considerações, o objetivo desse artigo é apresentar algumas reflexões que nos possibilitem compreender como se estabelece essas produções de verdade e suas implicações no campo de conhecimento das ciências humanas. $\mathrm{O}$ artigo será dividido didaticamente em duas partes: a primeira parte tem como eixo-norteador algumas considerações de Foucault sobre saber, poder e verdade e a segunda parte se desenvolve a partir das análises de Zemelman (2006) sobre o sujeito na produção do conhecimento numa realidade que envolve os paradigmas da racionalidade científica e a parametrização do pensamento. Mediante tais considerações, procuraremos, então, articular esses autores mostrando que a produção do conhecimento científico na área das ciências humanas pode ser um dispositivo de ação a serviço do biopoder que homogeneíza o espaço social e distribui os sujeitos conforme as circunstâncias.

\section{O SABER E O PODER NA PRODUÇÃo DE VERDADE}

Dreyfus e Rabinow (1995) ao comentarem analiticamente a obra de Michel Foucault destacam que a meta desse o autor era elaborar um estudo genealógico que favorecesse um diagnóstico preciso e imparcial das práticas sócio-históricas na qual o sujeito moderno se encontra completamente imerso, obediente e con- 
trolado por campos de forças oriundos do entrecruzamento do saber e do poder comandados pelo engendramento político, legitimando certas verdades que controlam todas as manifestações humanas no espaço social. Vale ressaltar que verdade, nessa perspectiva filosófica, não é resultado desse entrecruzamento, pois o poder e o saber se apropriam dela e a autentica em suas redes de operacionalidade, produzindo dispositivos disciplinares que suscitam no sujeito uma construção subjetiva que adquire materialidade e coerência atrelada a obrigações e deveres, obediência e servidão, constituindo, assim, procedimentos cuidadosos com a finalidade de manter a ordem, a estabilidade e o controle social.

$\mathrm{Na}$ concepção foucaultiana, o termo "genealogia" pode ser compreendido como uma ferramenta de desvelamento que permite elucidar as formações discursivas presentes em toda a produção de saber e poder que opera no espaço social e determina a produção de verdade na qual o sujeito se sujeita pacificamente de maneira inquestionável e absoluta. Dreyfus e Rabinow (1995) consideram, ainda, que a função da genealogia é assinalar a singularidade dos acontecimentos visando recordar "o passado da humanidade para desmascarar os hinos solenes do progresso. A genealogia evita, portanto, a busca de profundidade. Ela busca a superfície dos acontecimentos, os mínimos detalhes, as menores mudanças e os contornos sutis" (DREYFUS; RABINOW, 1995, p. 118).

Nesse sentido, o foco central da genealogia não é o aprofundamento analítico e interpretativo das formas discursivas presentes nas práticas sociais que governam os sujeitos em seu contexto histórico, submetendo-os a um adestramento estratégico a partir de um poder político que estabelece a universalidade dos enunciados de verdades às quais todos devem obedecer e aceitar sem quaisquer questionamentos. A função da genealogia, contudo, é lixar o verniz dessa produção de verdade e analisar as estratégicas políticas que se operam na invisibilidade dessas práticas sociais que controlam, distribuem e vigiam todas as ações dos homens em suas menores sutilezas.

[...] as questões tradicionalmente consideradas mais profundas e complexas, são literalmente as mais superficiais. Isso não significa, contudo, que sejam triviais ou sem importância, apenas que seu significado deve ser buscado nas práticas superficiais e não em profundidades misteriosas (DREYFUS; RABINOW, 1995, p. 119).

Desse modo, a genealogia não se preocupa com as coisas tangíveis e transcendentais exatamente porque elas são apenas ferramentas de manobras utilizadas pelo poder para distribuir os sujeitos no espaço social a fim de garantir a efetividade das práticas de dominação e controle. Foucault $(1979,1984)$ destaca que essas práticas de controle têm por finalidade administrar a vida dos sujeitos na sociedade visando manter o equilíbrio e a ordem pré-estabelecida por meio da ação normalizadora dos corpos que consiste num conjunto de medidas que possibilita governar, disciplinar, classificar, distribuir, hierarquizar, controlar, categorizar e equiparar os sujeitos pela diferença. 
O efeito da sanção normalizadora é complexo. Ele parte da premissa de que todos os indivíduos são formalmente iguais. Isso conduz a uma homogeneidade inicial a partir da qual se estabelece a norma de conformidade. Porém, uma vez posto este aparelho em movimento, há uma diferenciação e uma individuação cada vez mais sutis que separam e organizam os indivíduos objetivamente (DREYFUS; RABINOW, 1995, p. 175).

Desse modo, as heterogeneidades, visíveis a olho nu, como a inclusão, a exclusão e tantas outras formas de constituição da subjetividade parecem ser desconsideradas nesse campo de força minado pelo saber e poder porque a finalidade essencial da norma parece ser a homogeneização efetiva do corpo e do corpus sociais através de um mecanismo sutil de ação compreendido como "biopoder" (FOUCAULT, 1979). Segundo o autor, o “biopoder”, presente nas práticas sociais, produz estratégias de força a fim de efetivar verdades sobre o sujeito através do deciframento do corpo e da sexualidade (FOUCAULT, 1979). Nesse sentido, o biopoder pode ser compreendido como uma tecnologia de ação capaz de produzir procedimentos, saberes e verdades nas relações do sujeito no espaço social e que sustentam o corpo como objeto de investigação do poder. Dreyfus e Rabinow (1995) assinalam, ainda, que a finalidade do biopoder é fabricar corpos passíveis de serem controlados, manipulados, investigados e disciplinados, pois o objetivo é torná-los dóceis e produtivos em conformidade com as exigências administrativas do poder político distribuído em toda a rede de complexidade social.

Desse modo, o corpo, de fato, parece ser um elemento estratégico e importante onde o biopoder se movimenta, efetiva e organiza todas as suas ações no espaço social desde as formas aparentemente banais de relacionamentos interpessoais até os modos do sujeito se apresentar adequadamente na sociedade ou de produzir conhecimentos científicos. Conforme Dreyfus e Rabinow (1995), o corpo torna-se objeto de investigação do saber e do poder nas ciências humanas devido a sua capacidade de sujeição, cuja origem pode ser encontrada nas práticas de exame e confissão oriundas das instituições cristãs. Para esses autores, essas práticas de exame e confissão (o visto e o dito) parecem formular a verdade acerca do sujeito moderno que aceita o saber biológico sobre o corpo (exame) e as práticas adivinhatórias sobre a mente (confissão) como ciências irrefutavelmente inquestionáveis que produzem as verdades sobre si mesmo.

O fator causal dessa sujeição a tais saberes sobre o corpo e a mente parece estar relacionado com a inquietação que a sexualidade passou a exercer no início do século XIX sobre a subjetividade do sujeito a ponto de se tornar o lugar originário da verdade e sua razão ontológica de ser. Assim, a sexualidade nesse período passou a definir essencialmente o sujeito ao decifrar os desejos ocultos de si, bem como seu modo de ser, de relacionar e de se apresentar no mundo. Vale destacar que antes desse período a sexualidade parecia não ter tanta importância para a constituição das relações humanas e estava atrelada apenas à noção de 
sexo que cumpria, dentre várias funções, o matrimônio, a obrigação religiosa, a procriação da espécie, a transmissão da propriedade pelos laços consanguíneos que Foucault (1985) compreendia como "dispositivos de aliança".

Desse modo, a importância conferida à sexualidade no século XIX surgiu da separação do sexo com esses "dispositivos de aliança", se tornando o objeto mais instigante a ser decifrado pelos "mestres" do saber (clérigos e médicos) uma vez que a sexualidade, supunha-se, escondia as verdades ocultas do eu e definia a essência do sujeito. Consequentemente, essas atribuições conferidas à sexualidade iria incidir de maneira avassaladora nos processos de subjetivação uma vez que ela passa a ser objeto incessante da investigação científica produzida pelo entrecruzamento dos campos de força do poder e do saber. Segundo Foucault (1985), a sexualidade passou a ser motivo de preocupação nesse período devido, também, à proliferação de doenças que precisavam ser controladas de maneira a preservar a saúde e a identidade dos sujeitos sadios uma vez que as aberrações congênitas e o homossexualismo, por exemplo, tornaram-se objetos de investigação do biopoder por serem considerados problemas ligados à sexualidade.

Assim, as práticas investigativas acerca da sexualidade nesse período possibilitaram o surgimento das "ciências do psiquismo" que Foucault $(1985,1987)$ define como "ciências duvidosas" uma vez que elas formulam verdades questionáveis sobre o sujeito mediante as tecnologias de confissão (oriundas da Idade Média) cujo paradigma era quanto mais o sujeito falasse a respeito de si mesmo, mais a ciência saberia sobre ele e definiria sua condição ontológica. Portanto, a importância conferida à sexualidade no século XIX possibilitou a intensificação das tecnologias de confissão e autoexame da consciência, proporcionando a expansão do biopoder porque o sujeito para se autoconhecer necessitaria explicitar seus segredos mais íntimos e, para tanto, tornou-se objeto a conhecer e a ser decifrado.

Nesse sentido, o deciframento do sujeito pelas tecnologias de exame e confissão, originário das práticas cristãs, modificou o seu posicionamento no mundo, transformou suas relações consigo mesmo e a sociedade, delegando às ciências humanas a autoridade para formular enunciados de saber e verdade sobre si. Portanto, o que parece interessar nas tramas da subjetividade do sujeito é a hermenêutica de si através da sexualidade uma vez que ela estabelece a verdade ao decifrar as vicissitudes dos desejos mais íntimos do eu. Esse saber sobre a sexualidade confina o sujeito sobre si mesmo e libera ações políticas para promulgar sentenças universais no espaço social, disciplinando e governando todas as suas ações na invisibilidade do poder através de dispositivos de controle e segurança (FOUCAULT, 2008).

Com efeito, a partir do surgimento das diversas tecnologias de investigação (disciplina, exame e confissão), as singularidades dos sujeitos passam a ser ignoradas pelo biopoder que, engendrado nas estruturas sócio-políticas do Estado Moderno, parece se ocupar agora apenas com os interesses da coletividade, pois, trata-se de estratégias minuciosas que descentralizam ações, desconsideram as particularidades de cada sujeito nas redes de sociabilidade. Vale destacar que o Estado Moderno, segundo Foucault (1995), teve suas raízes basilares no "poder pastoral", ou seja, uma antiga tecnologia de poder proveniente das instituições 
cristãs na qual o clérigo tinha, dentre outras funções "altruístas", a responsabilidade de conduzir o rebanho à salvação. Nesse sentido, o Estado Moderno ao se apropriar das tecnologias do poder pastoral se constituiu para Foucault como uma máquina extremamente útil para o exercício efetivo do biopoder.

Mas eu gostaria de enfatizar o fato de que o poder do Estado (e esta é uma das razões de sua força) é uma forma de poder tanto individualizante quanto totalizadora [...] uma estrutura muito sofisticada na qual os indivíduos podem ser integrados sob uma única condição: que a esta individualidade se atribuísse uma nova forma, submetendo-a a um conjunto de modelos muito específicos. De certa forma, podemos considerar o Estado como a matriz moderna da individualização ou uma nova forma do poder pastoral (FOUCAULT, 1995, p. 236-237).

Desse modo, Foucault (1995) parece considerar que a produção de verdade sobre o sujeito é um desdobramento desse poder pastoral que tinha nas práticas confessionais a legitimação de deciframento do indivíduo, decretando enunciados valorativos (bom e mau, doente e sadio, por exemplo), a fim de torná-lo objeto analisável, categorizável e eminentemente previsível. Nesse sentido, pode-se dizer que a ação implacável do biopoder tem como estratégia tática objetificar o sujeito a ponto de forjá-lo em um corpo dócil, útil e produtivo a serviço exclusivo de seus interesses gerais.

Esta forma de poder aplica-se à vida cotidiana imediata que categoriza o indivíduo, marca-o com sua própria individualidade, liga-o à sua própria identidade, impõe-lhe uma lei de verdade, que devemos reconhecer e que os outros tem que reconhecer nele. É uma forma de poder que faz dos indivíduos, sujeitos. Há dois significados para a palavra sujeito: sujeito a alguém pelo controle e dependência e preso à sua própria identidade por uma consciência ou autoconhecimento. Ambos sugerem uma forma de poder que subjuga e torna sujeito a. (FOUCAULT, 1995, p. 235, grifo do autor).

Assim, uma das atribuições vinculadas ao biopoder parece ser "vigiar" os sujeitos na invisibilidade das estruturas sociais e "punir" todos aqueles que ousam desafiar os enunciados por ele emitidos, trabalhando na lógica da individuação fazendo o sujeito voltar sobre si mesmo a fim de se reconhecer e se distinguir dos demais. Nesse aspecto, o sujeito parece ficar à mercê de uma subjetividade construída pela apropriação de enunciados de verdade legitimados cientificamente e lhe outorgando o lugar a ser ocupado nas redes de sociabilidade, pois, conforme destacam Dreyfus e Rabinow (1995, p. 188):

[...] o indivíduo moderno - objetivado, analisado e fixado - é uma realização histórica. O poder não aplica seu saber, suas investigações, suas técnicas ao 
universal, mas ao indivíduo como objeto e efeito de um entrecruzamento do poder e do saber.

Portanto, a produção de verdade presente nas redes sociais é um mecanismo de ação estratégica a serviço do biopoder que sanciona enunciados sobre o sujeito e procura condicioná-lo a um posicionamento dogmático e fantasioso sobre a realidade mesmo havendo pontos de resistências nesse entrecruzamento do saber e do poder que podem proporcionar outros processos de subjetivação e uma reinvenção do social. Nesse sentido, Foucault (1979) esclarece que a cada ponto do poder há, também, um ponto de resistência correspondente, coexistindo, então, no mesmo plano, pontos de correlações de força e de agenciamentos de potência que podem provocar transgressões ou estremecerem os poderes e saberes instituídos. Mesmo assim, a maioria dos sujeitos parece se coadunar com os mecanismos de ação presentes nas redes do biopoder e, não resistindo a essas formas de operacionalidade, acaba por se tornar um produto polimorfo dessas práticas sociais objetivantes e castradoras que, endossadas pelas ações sócio-políticas do Estado, elaboram "dispositivos" de controle e vigilância na qual o poder e o saber se apropriam dos enunciados de verdade e os disseminam por toda a rede de interconexões.

Segundo Dreyfus e Rabinow (1995), o termo "dispositivo" no conceito foucaultiano pode ser compreendido como ferramentas de ação a serviço do biopoder na promulgação da verdade e do conhecimento engendrado nas práticas sociais. Portanto, de acordo com esses autores, o dispositivo é "definitivamente heterogêneo, incluindo os discursos, as instituições, as disposições arquitetônicas, os regulamentos, as leis, as medidas administrativas, os "enunciados científicos', 'as proposições filosóficas', a moralidade, a filantropia, etc" (DREYFUS; RABINOW, 1995, p. 134, grifos meus). Conforme podemos depreender, os dispositivos se encontram presentes nos entrecruzamentos do saber e do poder, incidindo na produção de verdade sobre o sujeito, a família e a sociedade além de controlar e supervisionar toda a produção de conhecimento, especialmente as atividades das ciências humanas que englobam as áreas da psicologia e da psiquiatria eleitas como as ciências da mente e autoridades máximas e absolutas no assunto com direito a emitirem pareceres contundentes e irrevogáveis acerca dos próprios sujeitos.

Portanto, a genealogia na perspectiva foucaultiana visa compreender as produções de verdade dessas práticas sócio-históricas que fabricam sujeitos dóceis, produtivos e sistematizados pela apropriação dos discursos aferidos pelo estruturalismo científico e que garante a sua sustentabilidade. Em outras palavras, a genealogia possibilita refletir acerca das ações do biopoder no espaço social interconectadas por uma ampla e complexa rede de significados e apropriações que regulamentam as verdades a serem incorporadas nos discursos dos próprios sujeitos. A Figura 1, a seguir, apresenta esquematicamente a ação do biopoder nessa rede de interconexões presentes em todo o espaço social. 


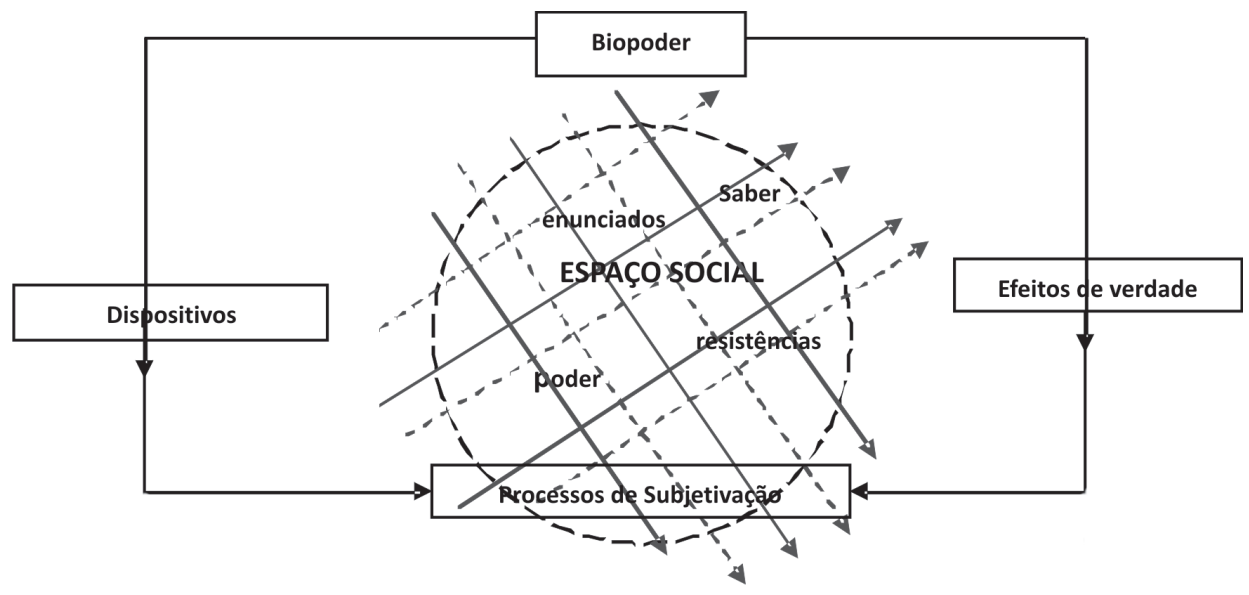

Figura 1 - Apresentação esquemática do biopoder no espaço social.

Conforme podemos observar no esquema apresentado na Figura 1, o espaço social se configura por uma complexa rede de interconexões na qual a ação do biopoder, provenientes do entrecruzamento do poder e do saber (esquematizado pelas setas contínuas), se apropria dos enunciados científicos e produz efeitos de verdade que incidirá de maneira avassaladora e radical nos processos de subjetivação do sujeito. Nessa rede de complexidade social, encontram-se também os dispositivos que regulamentam essas verdades fazendo com que o biopoder seja uma máquina em constante movimento operativo de lutas e embates na contenção das resistências (esquematizado pelas setas pontilhadas). Nesse esquema, a cada ponto de poder e saber corresponde um ponto de resistência correlato que precisa ser controlado para garantir a efetivação do exercício do poder e tornar a razão de sua operacionalidade. Portanto, é nesse emaranhado de complexificação distribuída em rede por todo o espaço social que os campos de força do poder e do saber disparam os dispositivos de controle que são responsáveis, também, pela normalização dos sujeitos.

Desse modo, podemos considerar mediante essas constatações que apesar de haver sempre uma força de contenção nos movimentos de operacionalidade do biopoder, há também possibilidades de reinvenção do sujeito a partir dos pontos de resistências que esse campo de força abriga em seu interstício durante o exercício imperioso do poder. Isso significa dizer que os agenciamentos de potência, presentes nos pontos de resistências, podem ser utilizados para burlar as interconexões instituídas pelo saber-poder e promover os sujeitos dos devires a partir de abalos sísmicos que apontem para uma outra forma de subjetivação capaz de proporcionar o cuidado e a autonomia de si.

Portanto, atuar nas brecha que esses campos de força oferecem possibilita o questionamento da produção de conhecimento e potencializa novas formas de se pensar a realidade do sujeito no espaço social contemporâneo em busca da ousadia e do inédito reprimidos pela ação implacável do biopoder. Nesse sentido, é interessante analisarmos que práticas científico-acadêmicas estão sendo pro- 
duzidas nas ciências humanas, onde se incluem as ciências psíquicas, para que não caiamos na reprodução desses modos de objetificação do sujeito e fiquemos tendenciosamente condicionados à repetição e ao reducionismo teórico que propagam efeitos de verdade e da individualização.

A conclusão seria que o problema político, ético, social e filosófico de nossos dias não consiste em tentar liberar o indivíduo do Estado nem das instituições do Estado, porém nos liberarmos tanto do Estado quanto do tipo de individualização que a ele se liga. Temos que promover novas formas de subjetividade através da recusa desse tipo de individualidade que nos foi imposto há vários séculos (FOUCAULT, 1995, p. 239).

Entretanto, acreditamos que essas novas formas de subjetividade só poderão ser possíveis quando a racionalidade científica do academicismo seja questionada e repensada, pois, os códigos técnicos e a linguagem pré-estabelecida formalizam e absolutizam o rigor metodológico na reprodução das padronizações conceituais além de confinar o sujeito em uma realidade totalizadora que aciona continuamente a operacionalidade do biopoder. Todavia, como se dá a construção do conhecimento nesse contexto e como criar alternativas que não reproduzam modismos científicos no espaço social e efetivem os mecanismos do biopoder? Como construir uma outra subjetividade que possibilite ao sujeito a autonomia de si? É o que pretendemos refletir a seguir.

\section{O SUJEITO E A CONSTRUÇÃO DO CONHECIMENTO}

Para que possamos problematizar o lugar cômodo do academicismo científico e pensar alternativas para outras possibilidades de produção do conhecimento e da subjetividade, Zemelman (2006) propõe novos parâmetros para essas questões a partir da recuperação do sujeito pensante e o conjunto de suas faculdades que incluem a emoção, a intuição ou as prefigurações imaginativas. Para isso, o autor considera importante uma reformulação da linguagem da ciência e seus pressupostos metodológicos a começar pelo abandono do lugar-comum pautado na parametrização do pensamento e na ideia de neutralidade investigativa. Nesse sentido, a questão central é potencializar o conhecimento no próprio sujeito para que este possa se posicionar mediante a realidade de forma mais participativa e menos protocolada à razão instrumental que limita, padroniza e neutraliza, em nossa opinião, as possibilidades de reinvenção de si e do autocuidado conforme os efeitos de verdade presentes nos dispositivos do biopoder.

Contudo, para que seja possível a construção de uma nova linguagem no conhecimento científico, Zemelman (2006) considera importante contextualizar o momento histórico através de um ato de pensamento que possibilite ao sujeito questionar a realidade, abrir-se ao inédito e saber pensar a partir do desconhecido sem qualquer posicionamento valorativo ou ideológico. Isso significa dizer que a construção do conhecimento na concepção desse autor deve ser um projeto sempre inacabado e em constante transformação para que não se reduza a mais um 
modismo a ser incorporado pela ciência e se enraizar na efetivação de verdades. Assim, para que a construção de um outro conhecimento seja viável, Zemelman (2006) considera importante o sujeito atuar no espaço social ou realidade externa onde se processa a história da civilização.

A realidade sócio-histórica tem significados múltiplos. Não é uma realidade clara, inequívoca, com uma presença transparente que se poderia abordar através da construção de teorias. As visões de futuro não são extrapolações teóricas, porque aludem a um excedente de realidade que se procura tornar tangível a partir de espaços em que esteja presente a prática humana. Estes espaços são os momentos históricos (ZEMELMAN, 2006, p. 459).

Conforme podemos depreender, há diversos elementos presentes nos momentos históricos que ainda não foram explorados pelo conhecimento porque este parece ter se limitado a permanecer estagnado a um pensamento teórico pautado pelo exclusivismo da ciência positivista que reconhece a presença de um único tipo de sujeito, aquele da razão instrumental, e limita outras possibilidades de intervenção sobre a realidade externa ou espaço social. Portanto, a construção de um outro conhecimento na perspectiva desse autor se dará a partir de uma ousadia de transgredir os sentidos já cristalizados pelo positivismo a fim de se evitar o caráter de generalização e efetivação de sujeitos homogêneos nos discursos da ciência. Daí a importância de explorar novas formas de relação de conhecimento que transgrida os códigos teóricos circunscritos e herdados sem reflexão crítica, pois, na medida em que esses conceitos "nos pareçam rigorosos e coerentes por conformarem discursos lógicos e persuasivos... estamos a ocultar-nos no interior dos discursos sem dele podermos sair, por, em vez da realidade histórica concreta, estarmos a pensar uma realidade inventada" (ZEMELMAN, 2006, p. 462).

Mediante tais considerações assinaladas, a proposta do autor é potenciar o conhecimento no próprio sujeito para que este possa se posicionar frente à realidade de maneira mais crítica e menos formal visando um rompimento com aquilo que se aceita sem questionamento e torna a subjetividade, segundo nossa opinião, circunscrita a efeitos homogeneizadores de verdade não condizentes com a realidade in natura. Para que isso seja possível, torna-se necessário, conforme o autor, um afastamento do sujeito em relação à sua determinação e às teorizações dadas a priori acerca do objeto de conhecimento a fim de formular uma ampliação da subjetividade que enriqueça o ângulo a partir do qual se constrói o pensamento.

Portanto, pensar as circunstâncias que estão ao redor e além do objeto colocado sob medição é, conforme Zemelman (2006), abrir-se ao inédito, pois, quando se considera que o objeto possui uma dimensão histórica em constantes mutações e flutuações no tempo, o conhecimento, enquanto organização de conteúdos, ganha novos sentidos para aquele momento histórico específico e possibilita outras formas de pensar a realidade sem prospecção de permanência absoluta, evitando-se, assim, a possibilidade de naturalizá-lo e perpetuá-lo como verdade absolutamente inquestionável. Nesse sentido, o autor acredita que para produ- 
zir novos conhecimentos e lhes dar outros sentidos é necessário potencializar a reflexão crítica no sujeito perante o determinismo científico para que ele possa ultrapassar a significação estabelecida no campo teórico e resignificar os mesmos objetos circunscritos nessa formalidade científica.

Desse modo, a construção de novos paradigmas científicos não deve se restringir a meras explicações dos fenômenos porque implica a compreensão da realidade como um atravessamento de momentos sócio-históricos multifacetados que se desdobram em circunstâncias ambíguas e incapazes de serem desvendadas pela construção unilateral de teorias delimitadas e reconhecidas universalmente. Tratase, portanto, de questionar o inquestionável tomando as devidas precauções para evitar que os novos significados a serem descobertos e incorporados pelos sujeitos sejam capturados pelos discursos homogeneizadores das ciências, transformando esses significados num modismo mitificador e reprodutor de verdades absolutas.

Isto ocorre com mais frequência no âmbito do conhecimento sócio-histórico do que no das ciências naturais, posto que naquele deparamos com a necessidade de parâmetros derivados das exigências da ordem social, mas também - o que já é generalizável a todo conhecimento científico - com as inércias que dão lugar a uma configuração da realidade objetiva enquanto sinônimo de sua constituição como um campo neutro (ZEMELMAN, 2006, p. 464).

Conforme podemos observar nas considerações do autor, parece que a ideia de neutralidade nas ciências humanas e sociais precisa ser devidamente questionada se quisermos construir novos espaços de possibilidades para a elaboração do conhecimento que seja capaz de se desvincular das armaduras que dão sustentabilidade à razão instrumental. Nesse sentido, podemos concluir que se a realidade for definida por exigências conceituais que limitam os sujeitos de acordo com as pré-determinações formuladas, então, as ciências humanas podem estar sendo estruturadas de maneira que não são dados esses espaços de possibilidades para todos os sujeitos descobrirem as suas potencialidades a ponto de despertarem a capacidade de cuidar-se de si mesmos e construírem a sua própria subjetividade. Desse modo, o autor critica o determinismo científico que apenas reproduz os discursos ideológicos vigentes, impossibilita a elaboração de novos conhecimentos e circunscreve o sujeito ao formalismo teórico e meramente convencional.

Associamos esta posição à ideia de um sujeito erguido perante as suas circunstâncias; capaz de se colocar perante o indeterminado, entendendo-o como o grande desafio constituído pela complexidade, concebida como articulação dinâmica de relações. Daqui decorre que a complexidade alude ao excedente de realidade, de modo que o conhecimento incide na apreensão entre a determinação-apropriação e o excedente ainda sem forma, isto é, sem nome, mas sempre presente na medida em que o conhecimento é um movimento que rompe com os limites conceituais (ZEMELMAN, 2006, p. 465). 
Entretanto, como construir um novo conhecimento e possibilitar outras formas de subjetivação? O que é a verdade no campo das ciências humanas? Reprodução de um conhecimento que não se questiona ou apropriações de conceitos para efetivar poder e saber sobre os sujeitos? Afinal, como que o meio acadêmico-científico pode estimular as potencialidades do sujeito para que este desperte sua curiosidade perante o indeterminado e ouse a pensar e encontrar alternativas ao que nos foi imposto há vários séculos e de forma inquestionável pelas práticas sociais objetivantes acerca da verdade? A esse respeito, Zemelman (2006) aposta, por exemplo, numa pedagogia acadêmica que seja capaz de recuperar o sujeito no conjunto de suas faculdades constitutivas através de um processo ensino-aprendizagem presente em todos os setores de produção do conhecimento, mas que saia da zona de conforto eminentemente enraizada pela cultura epistemológica de caráter positivista.

Nesse sentido, a proposta é favorecer que o sujeito reflita sobre a construção do conhecimento, atue sobre ele para elaborar novas possibilidades ainda inéditas ou inexploradas no campo das ideias, pois, o conhecimento in natura se encontra, segundo autor, no excedente de realidade externa. Em nossa opinião, acreditamos que essa realidade externa equivale ao espaço social complexificado e pode ser decodificada no pensamento de Zemelman como aquilo que foge ao domínio visível e tangível do sujeito mas que incide sobre ele possibilidades de transgressões. Da mesma forma, o excedente de realidade corresponderia aos pontos de resistência ainda inéditos e em estado de latência a serem potencializados nas redes de interconexões do biopoder.

Desse modo, o excedente de realidade pode ser compreendido como pontos de latência aguardando o momento de erupção nos interstícios que os campos de força do saber e do poder oferecem quando se encontram em exercícios operativos visando controlar e dissipar as dissensões. Com efeito, a construção do conhecimento se daria nos agenciamentos de potência presentes no encontro desses pontos possibilitando, inclusive, outros processos de subjetivação, conforme ilustrado na Figura 2 a seguir.

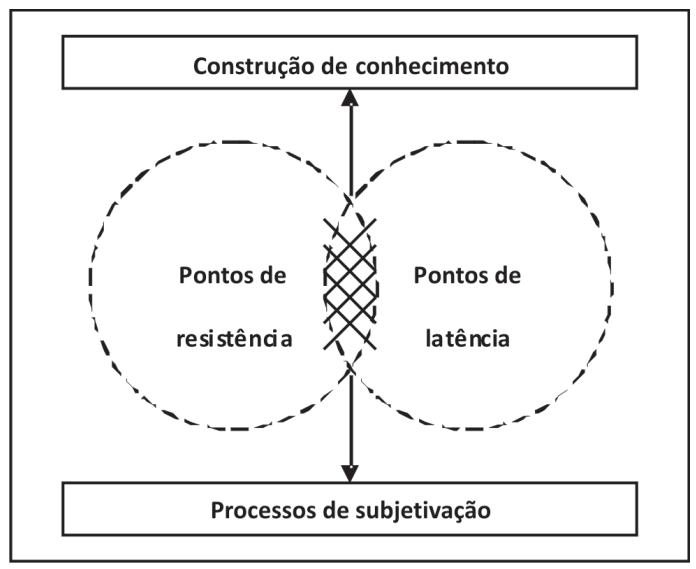

Figura 2 - Apresentação esquemática da construção de conhecimento e processos de subjetivação. 
Portanto, podemos conjeturar que parece haver uma possível relação entre os pontos de resistência presente nos campos de força do exercício de poder na perspectiva foucaultiana com esse excedente de realidade ou pontos de latência na perspectiva de Zemelman (2006). Nesse sentido, podemos admitir que a potencialização do conhecimento inédito defendido por Zemelman pode favorecer ao sujeito outras formas de subjetivação e possibilitar também que este adquira as condições necessárias para o cuidado de si desvinculando o corpo e a mente como propriedades exclusiva do saber nas ciências do psiquismo. Nessa linha de raciocínio, o sujeito pode dar um outro sentido à sua existência e fazer-se presente na civilização como portador de historicidade.

Nesse contexto, o conhecimento precisa ser posto em movimentos constantes sem se delimitar a demarcações específicas a fim de não cair nas artimanhas instituídas pelas forças operativas do biopoder para que se possa constituir, assim, segundo Foucault (1979), uma nova política da verdade desvinculada das formas de hegemonia no interior das quais ela funciona. Isso pode ser pensado e potencializado não somente no meio acadêmico-científico, mas, sobretudo, nos pontos de resistência que oferece amplas possibilidades de agenciamentos de potências mediante os imperativos homogeneizadores presentes nos modos de produção da subjetividade capitalista como pode ser observado, por exemplo, nos movimentos de transgressões aos poderes-saberes constituídos e circulantes no espaço social.

Dito de outra forma, a potenciação do conhecimento pode, a partir dos pontos de latência e resistência, despertar o sujeito para a construção de uma outra subjetividade ainda possível e em sintonia com o devir. Portanto, a complexidade social pode ser considerada como um espaço de possibilidades de transformação do conhecimento a partir do momento em que o sujeito se distancie dos códigos técnicos e das linguagens utilizadas pelos paradigmas estabelecidos que formaliza e absolutiza o rigor metodológico como único caminho na produção da verdade, impossibilitando-o de ser co-autor do processo histórico em constante mutação e desenvolvimento. Para que seja possível a ação do sujeito na realidade histórica visando à construção de novos conhecimentos, Zemelman (2006) acredita ser necessário potencializar um tipo de pensamento que saia dos limites dos códigos teóricos em busca de novas significações, ou seja, um pensamento que transgrida os paradigmas científicos formulados e favoreça a capacidade de ação dos próprios sujeitos na realidade histórica e que pode ser potencializada, em nossa opinião, através dos pontos de resistências.

O que está em jogo é a capacidade de formular um problema, pôr em prática uma argumentação que não se deixe enredar nos conhecimentos já codificados; sermos críticos daquilo que nos sustenta no plano teórico, ou seja, sermos capazes de nos distanciarmos tanto dos conceitos que manejamos como da realidade observada. Ou seja, temos a obrigação de nos distanciarmos das teorias que, de uma maneira ou de outra, já conhecemos, a fim de não incorrermos numa redução da realidade, mas também de questionar o empírico, o que observamos, porque este pode não ser o que é relevante. (ZEMELMAN, 2006, p. 464). 
Como podemos observar, o objetivo é levar o sujeito a não aceitar o que está estabelecido a priori como verdadeiro, mas a romper com os limites do que foi anteriormente estabelecido. Trata-se, enfim, de uma incorporação do sujeito na construção do conhecimento para que este compreenda cada vez mais a sua importância frente às circunstâncias sócio-históricas e descubra as opções de sentido que se ocultam, a nosso ver, por trás das lógicas instituídas nos campos do saber e do poder. Essas incorporações possibilitariam uma nova tomada de consciência para o sujeito e não permitiria que o pensamento fosse encarcerado em estruturas pré-determinadas, sendo necessário, contudo, atentar quanto ao fechamento de significados e a olhar para o momento histórico como algo sempre aberto para o desconhecido. Portanto, torna-se fundamental um distanciamento das teorias já conhecidas para não correr o risco de reproduzir ou confinar a construção do novo conhecimento aos paradigmas mitificadores da racionalidade científica.

Assim, podemos hipotetizar que há uma possível relação entre os efeitos de verdade veiculados no biopoder nas leituras de Foulcault $(1979 ; 1984 ; 1985$; 1995) com os paradigmas científicos apresentados por Zemelman (2006). Ambas as leituras parecem detectar o confinamento do sujeito a estruturas pré-determinadas pelo pragmatismo científico. Nesse sentido, os autores parecem ser unânimes ao endossarem a necessidade de abandonar o pré-estabelecido rumo à ousadia de se pensar o inédito, tanto no campo da subjetividade, quanto na produção do conhecimento, pois, o que parece ser fator comum na análise desses autores é, de fato, o questionamento dos mecanismos de operacionalidade das práticas sociais e a abertura do pensamento ao indeterminado e provocador que possibilitem a descoberta de outros sentidos e significados para a própria condição humana.

Nesse sentido, parece ficar claro que verdade e racionalidade científica estão presentes no entrecruzamento do saber e do poder e são utilizadas como ferramentas de manobra na promulgação de enunciados sobre o sujeito e sua subjetividade. Isso significa dizer que conhecimento e verdade parecem ser técnicas que o biopoder se apropria para controlar toda a dinâmica da ordem social e distribuir os sujeitos conforme suas necessidades e conveniências. Portanto, para possibilitar novos modos de subjetivação e abandonar o determinismo científico que também produz certas "verdades" conforme os padrões socialmente aceitáveis, tornam-se necessário a ousadia para questionar o inquestionável a partir da recusa de uma racionalidade imposta pela parametrização do pensamento, pois, somente assim é que será possível ao sujeito se descobrir e avançar na construção de uma outra história.

Em termos psicológicos, trata-se de algo muito profundo: atrever-se a estar em desassossego, a perder a calma ou a paz interior. Quem a tal não se atrever não poderá construir conhecimento; quem procurar manter-se na sua identidade, na imobilidade e no seu sossego construirá discursos ideológicos, mas não conhecimento; armará discursos que o reafirmem nos seus preconceitos e estereótipos, na rotina e no que crê ser verdadeiro, sem o pôr em causa (ZEMELMAN, 2006, p. 464). 
Desse modo, para se pensar novas possibilidades de conhecimento e subjetividade no contemporâneo, conforme as considerações apresentadas, torna-se necessária potencializar as qualidades do sujeito para que ele possa, num processo de constantes mutações, conquistar a autonomia de si a fim de atuar no plano sócio-político e possibilitar a elaboração de outros significados que propicie uma reinvenção do social onde a originalidade do "eu" adquira a espontaneidade suficiente para se expressar de forma mais autêntica e segura das imposições regulamentadas e administradas pela tecnocracia científica. Isso exige de nós, como produtores de conhecimento, o abandono da comodidade formal do academicismo pautado, a priori, em teorias objetivantes rumo a uma nova organização no campo das ideias que possibilite aberturas ao inédito e provoque o desassossego a fim de avançarmos na elaboração de novos paradigmas que proporcione ao sujeito o resgate da autonomia de si e o desclausure das práticas sociais objetivantes.

\section{Conclusão}

Como vimos, o entrecruzamento do poder e do saber produz efeitos de verdade que individualiza e, ao mesmo tempo, totaliza o sujeito nas estruturas políticas através de tecnologias disciplinares cujo objetivo principal é forjar um corpo dócil e produtivo que permita a distribuição, a organização e a supervisão de todos no espaço social. Assim, parece que o fator comum nas leituras de Foucault (1995) e Zemelman (2006) é favorecer possibilidades para os dilemas do sujeito contemporâneo no sentido de promover uma transformação ético-estética e política que o desvincule desse determinismo endossado pela racionalidade científica e parametrização do pensamento.

Essa perspectiva nos induz a pensar que as ciências humanas, especialmente a psicologia e a psiquiatria, parecem ser reprodutoras desses efeitos de verdade sobre o sujeito, pois o conhecimento emitido por elas é resultante desses atravessamentos do saber e do poder ao se apropriarem dos enunciados de verdadeiro e falso, normal e patológico, apto e não apto, por exemplo, utilizando-os como instrumentos de trabalho para a perpetuação de uma racionalidade científica eminentemente normalizadora que mantém a ordem pré-estabelecida a fim de garantir a sua estabilidade como podem ser constatados nos testes de psicodiagnósticos, recrutamento e seleção, laudos forenses, sanidades mentais, etc. Portanto, a questão crucial da psicologia, pelo menos no contexto social contemporâneo, seria problematizar até que ponto esses testes e diagnósticos definem a verdade sobre o sujeito ou se apenas são ferramentas de manobra a serviço do biopoder. Por isso, acreditamos que as ciências psicológicas precisam repensar suas práticas e o seu lugar na produção de conhecimento e verdade sobre o sujeito para que não caia na lassidão reprodutiva dos emaranhados objetivantes dessas práticas sociais.

Isso implica em abandonarmos ou pelo menos questionarmos alguns paradigmas que definem essa ciência para ousarmos a pensar o novo e o inédito a fim de elaboramos novos significados para a existência humana ou até mesmo outros paradigmas. Desse modo, relativizar a verdade na produção de conhecimento em psicologia e nas ciências humanas em geral requer, além de um posicionamento 
crítico frente à realidade, uma transformação das práticas sociais objetivantes e historicamente construídas a partir das próprias potencialidades dos sujeitos, pois, somente assim, é que conseguiremos elaborar outros processos de subjetivação capaz de estremecer as instâncias instituídas nos campos do saber e do poder que nos prendem aos modos de produção do racionalismo científico e nos condicionam a pensar de maneira convencional e absolutamente tecnicizada.

Com efeito, desabsoluticizar o sujeito na realidade produzida por essas práticas sociais objetivantes pode favorecer os pontos de latência presentes em sua essência humana e ganhar importância histórica. Portanto, torna-se necessário uma reflexão crítica na nossa produção de conhecimento para que saibamos relativizar, senão abandonar, nossas verdades construídas em torno do pensamento instrumental de maneira a não cairmos nas armadilhas reprodutivas do reducionismo científico presente nas estruturas políticas do biopoder. Quando, de fato, alcançarmos essa maturidade intelectual e acadêmica poderemos, então, promover novos conhecimentos no cotidiano voltado ao bem comum e que possibilite a reinvenção do social com outros significados para a subjetividade e a própria condição humana.

\section{REFERÊNCIAS}

DREYFUS, H. L.; RABINOW, P. Michel Foucault, uma trajetória filosófica: para além do estruturalismo e da hermenêutica. Rio de Janeiro: Forense Universitária, 1995.

FOUCAULT, M. Microfisica do poder. Rio de Janeiro: Graal, 1979.

FOUCAULT, M. Vigiar e punir. Petrópolis: Vozes, 1984.

FOUCAULT, M. História da sexualidade: a vontade de saber. Rio de Janeiro: Graal, 1985. v. 1.

FOUCAULT, M. O nascimento da clínica. Rio de Janeiro: Forense Universitária, 1987.

FOUCAULT, M. Território, segurança, população. São Paulo: Martins Fontes, 2008.

FOUCAULT, M. O sujeito e o poder. In: DREYFUS, H. L.; RABINOW, P. (Org.). Michel Foucault, uma trajetória filosófica: para além do estruturalismo e da hermenêutica. Rio de Janeiro: Forense Universitária, 1995. p. 231-249.

ZEMELMAN, H. Sujeito e sentido: considerações sobre a vinculação do sujeito ao conhecimento que constrói. In: SANTOS, B. S. (Org.). Conhecimento prudente para uma vida decente: um discurso sobre as ciências revisitado. São Paulo: Cortez, 2006. p. 457-468.

Recebido em: setembro de 2009

Aceito em: agosto de 2010 